\title{
AGRO- METEOROLOGICAL INDICES IN RELATION TO PHENOLOGY AND YIELDS OF PROMISING WHEAT CULTIVARS IN CHITWAN, NEPAL
}

\author{
Lal P. Amgain ${ }^{1}$
}

\begin{abstract}
Agro-meteorological indices are the major yield governing factors especially under rainfed ecosystem. The major agro-meteorological indices (phenology, and heat and radiation use efficiencies) of four wheat cultivars were evaluated from the rainfed field experiment (2008-09). The experiment was conducted in RCBD with three replications. The total rainfall received during the winter season (1994-95 to 2008-09) showed satisfactory winter rainfall during wheat growing season except year 2008-09. The agro-meteorological results indicated that the number of days required to attain different phenological stages were comparatively longer in early sowing than the late sown wheat. None of the wheat cultivars could show stable yield in late planting conditions suggesting early planting for higher yield. Early sowing wheat achived the higher and stable heat, radiation and heliothermal indices thus resulting into higher grain yield. The agro-meteorological indices could therefore be helpful in predicting the phenolgoy, growth and yields of wheat. However, more research is needed in other agro-ecological areas to validate the output further.
\end{abstract}

Key words: Agro-meteorological indices, growing degree days, heat use efficiency, helio-thermal unit, phenology, wheat

\section{INTRODUCION}

Weather variability is considered one of the major factors of inter-annual variation of crop growth and yield in all environments and it is more important in rainfed situation. The adverse agro-meteorological events like extreme hot and cold temperatures, the lesser brighter sunny days and irregular and unequal distributions of rains are the major factors for the decreasing growth and yields of any field crops especiallyunder rainfed environment. Rainfalls being vital, the growth phases of any variety of crops are determined basically with growing season in which the atmospheric ambient temperature and solar radiation are considered the major governing factors (Sastry et al., 2000). The planting of most of the crops in Nepal is rainfall dependent and the shift in sowing dates hence directly influences both the thermo and photoperiod. This in consequence has a great bearing on the phasic development and partitioning of the dry matter. Quantification of these effects may help in determining the sowing time and match the phenology of crop in specific environment to achieve higher heat and radiation use efficiencies.

Temperature based agro-meteorological indices such as growing degree days (GDD) and helio-thermal units (HTU) have been reported quite useful in predicting

\footnotetext{
${ }^{1}$ Assistant Prof . of Agronomy, IAAS Rampur, Chitwan email-amgain@gmail.com
} 
the growth and yield of crops (Dooraiswamy and Thompsosn 1982, Jones et al. 2003). Other researchers also found the influence of temperature on phenology and yield of crops and expressed through accumulated heat unit system (Sikdar, 2009; Rao et al., 1999; Rao and Singh, 2007). Heat and radiation use efficiencies in terms of dry matter or yields are important aspects which have great practical applications. The total heat and radiant energy available to any crop is never completely converted to dry matter under even at the most favorable agroclimatic conditions. Moreover, the efficiency of conversion of heat and radiant energy into the dry matter depends upon the genetic factors, sowing time and crop type (Rao et al., 1999). Hence, the knowledge on the calculation of the growing degree days and their further mathematical derivations like helio-thermal unit (HTU), and heat and radiation use efficiencies (HUE and RUE) is the basic principle to understand the phenology and the proper planting times could be for different crop varieties over the spatial and temporal variations (Sreenivas et al., 2010).

Wheat is the third most important staple cropmainly grown in rice-wheat sequence in central Terai of Nepal. Being the dominance of rainfed agriculture system, Nepalese farmers rarely grow wheat on time by which there is marked reduction in yield (NWRP, 2010). The delayed planting of long duration photoinsensitive rice cultivars due to late onset of monsoon resulting late rice harvesting is causing delay in wheat sowing under rice-wheat system. The late planted wheat thus appeared to be affected by poor germination and post anthesis heat stress which reduces yield dramatically (Giri, 1998). November 15 is reported to be the optimum date of sowing wheat in Terai regions of Nepal and deviation from this date results nearly $30-50 \mathrm{~kg} /$ day/hectare reduction in yield depending upon climatic conditions (NWRP, 2010). It is also reported that about $30 \%$ of wheat area is under late planting in Nepal (Hobbs, 2000). It has also been reported that the average productivity and profitability of the rice-wheat system is quite low than its potential and the sustainability is at risk. The shorter growing duration, between sowing to harvesting of wheat was resulting for lesser growing degree days and unstable and low heat and radiant use efficiencies (Sreenivas et al., 2010, Reddy et al., 2004). There are several reports on sowing time and crop yield on rice and wheat (Giri, 1998) and winter maize (Amgain, 2011) but very few has analyzed the specific reasons of lower yield under late planting conditions in Nepal based on an agro-meteorology and physiological factors. Therefore, an attempt has been made to study the phenological behavior, and heat and radiation use efficiencies in prominent wheat cultivars for obtaining higher, stable and sustained grain yield.

\section{MATERIALS AND METHODS}

The major agro-meteorological indices (phenology, and heat and radiation use efficiencies) of wheat were evaluated from the rainfed field experiment (2008-09) done at Agronomy Farm of Institute of Agriculture and Animal Sciences Rampur Campus Rampur, Chitwan ( $27^{\circ} 37^{\prime} \mathrm{N}, 84^{\circ} 25^{\prime} \mathrm{E}$ and 256 masl.). Four diverse wheat cultivars (RR-21, NL-297, BL-1473 and BL-1022) with early, mid and late maturity days were sown at three different dates (Nov 15, Dec 1 and Dec 15). The 
experiment was conducted in RCBD with three replications having slightly acidic ( $\mathrm{pH}$ 6.5) sandy loam soil with27.33\% soil moisture at field capacity, low organic carbon $(0.45 \%)$ and total soil $\mathrm{N}(0.20 \% \mathrm{~N})$, and medium phosphorus $(23.2 \mathrm{~kg} / \mathrm{ha})$ and potassium $(157.5 \mathrm{~kg} / \mathrm{ha})$. The records on the major phenological stages (emergence, crown root initiation (CRI), flowering, grain filling and physiological maturity) and yield and dry matter has been taken as standard international protocol given for wheat by CIMMYT, Mexico. Ten fixed plants in each plot were randomly selected from emergence and fixed up to the physiological maturity stages to visualize their different pheno-phases and $75 \%$ developmental stages have been marked. The standard package of practices was followed to grow wheat (Reddy, 2005). The daily weather data were collected from the Meteorological Observatory of National Maize Research Program, Rampur, Chitwan and the rainfall data of the last 15 years (1994-95 to 2008-09) has been compared to fix the normal sowing of wheat (Table 1). The average mean temperature and total sunshine hours attained by the various wheat cultivars from sowing to physiological maturity have been depicted in Figure 1 and 2, respectively. Similarly, the average temperature and mean sunshine hours from one developmental stage to the other stage for a particular planting date and cultivar was also taken for the further mathematical expressions (Rao et al.,2000; Singh et al., 1998; Ritchie and Nesmik, 1991).

1. Growing degree days $(G D D)=\{(T \max +T \min ) \div 2\}-T b$

$$
\left(\mathrm{Tb}=\text { Base temperature }=10^{\circ} \mathrm{C}\right)
$$

2. Helio-thermal unit $(\mathrm{HTU})=\mathrm{GDD} \times$ Duration of sunshine hours

3. Heat use efficiency $(\mathrm{HUI})=$ Biomass yield $(\mathrm{kg} / \mathrm{ha}) \div \mathrm{GDD}$

4. Helio-thermal unit use efficiency $($ HTUE) $=$ Biomass yield $(\mathrm{kg} / \mathrm{ha}) \div \mathrm{HTU}$

5. Radiation use efficiency $(\mathrm{RUE})=$ Biomass yield $(\mathrm{kg} / \mathrm{ha}) \div$ Radiation hours

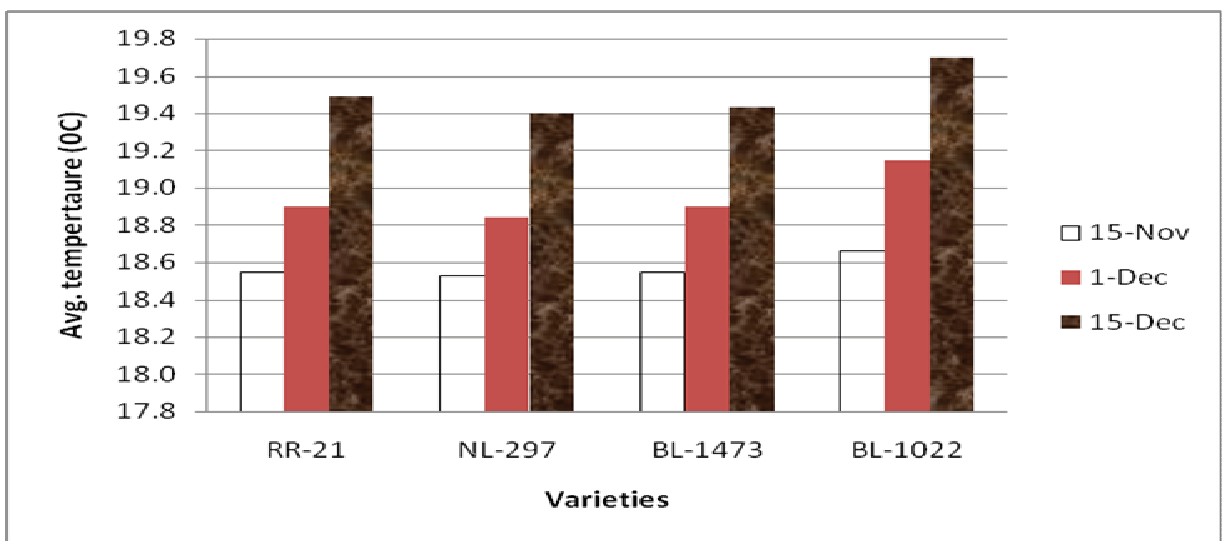

Figure 1. Average temperature during growth period of various wheat cultivars under different sowing dates 


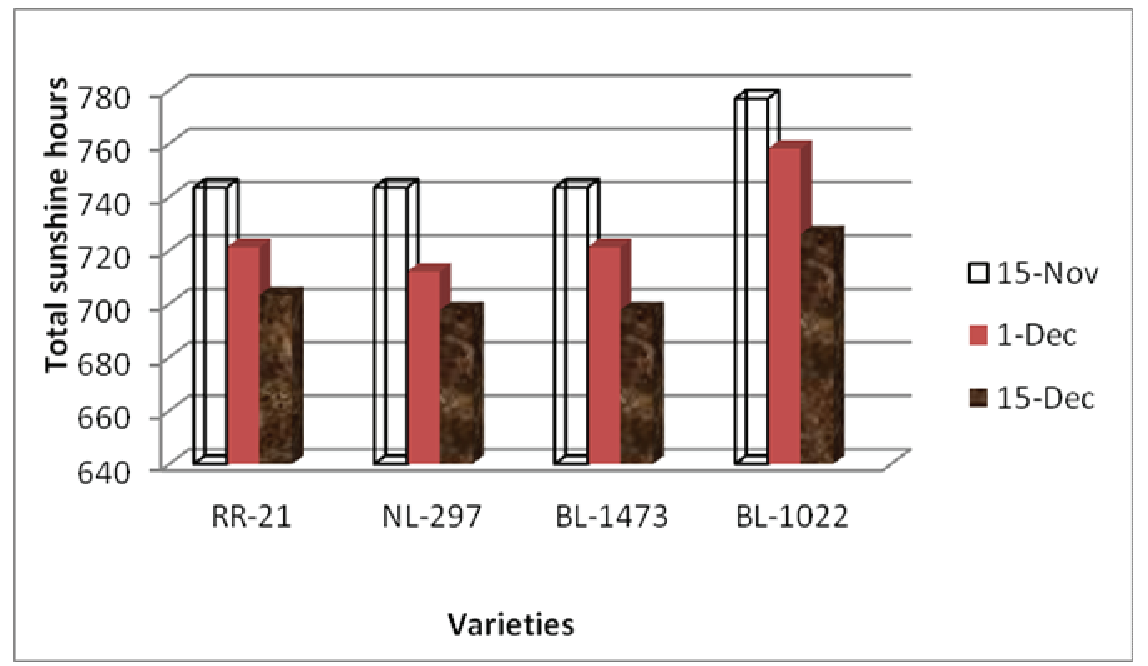

Figure 2. Total sunshine hours received by various wheat cultivars under different sowing dates

\section{RESULTS AND DISCUSSIONS}

\section{RAINFALL PATTERN}

The total monthly rainfall pattern of Chitwan over the last 15 years (Table 1) revealed that rainfed wheat could be a successful package to the farmers of central-terai region of Nepal providing life saving irrigation at critical growth stages. Except 2008-2009, the total amount of rainfall received during the wheat growing period was average of $140.8 \mathrm{~mm}$ and considered effective for growing wheat successfully. Though, wheat requires about $400-500 \mathrm{~mm}$ of water for its successful growth and development, the interval of rainfall and crop growth stages are more critical (Reddy, 2005). The crops planting on all dates did not receive any effective rainfall in 2008-09, however, the growth was optimum upto the harvest stage of crop due to the higher moisture holding capacity of the soil (27.33\% soil moisture at field capacity) and some significant amounts of dew occurred at night during the crop growing season. Sharma et al. (1984) has also mentioned the successful growth of rainfed wheat under inner-terai region of central Nepal.

\section{Phenology, growing degree days and helio-thermal units}

The phenology, growing degree days, and helio-thermal unit results revealed that different phenological stages differed significantly from cultivar to cultivar and planting dates (Table 2). The stable temperature and sunshine hours from early vegetative phases to physiological maturity of all cultivars resulted in increased number of days for attaining different phenological stages under normal planting (Figure 1 and 2). 
Table 1. Decadal history of monthly total rainfall pattern during winter in Chitwan

\begin{tabular}{llllllll}
\hline Year/ month & Nov & Dec & Jan & Feb & Mar & Apr & Total \\
\hline $1994-95$ & 0.0 & 0.0 & 1.5 & 22.9 & 5.9 & 36.0 & 66.3 \\
$1995-96$ & 1.7 & 3.5 & 55.7 & 40.4 & 0.0 & 6.0 & 107.3 \\
$1996-97$ & 0.0 & 0.0 & 13.4 & 1.5 & 2.9 & 144.6 & 162.4 \\
$1997-98$ & 7.6 & 146.0 & 4.4 & 13.2 & 87.2 & 88.3 & 346.7 \\
$1998-99$ & 8.2 & 1.0 & 0.4 & 0.0 & 0.0 & 10.1 & 19.7 \\
$1999-00$ & 0.2 & 0.0 & 0.8 & 9.8 & 24.9 & 7.6 & 43.3 \\
$2000-01$ & 6.4 & 0.0 & 1.6 & 18.6 & 0.8 & 67.4 & 94.8 \\
$2001-02$ & 20.4 & 0.0 & 31.9 & 28.3 & 45.6 & 57.7 & 183.9 \\
$2002-03$ & 44.6 & 0.0 & 35.1 & 59.4 & 62.0 & 58.7 & 259.8 \\
$2003-04$ & 79.8 & 10.7 & 62.7 & 0.0 & 0.0 & 180.2 & 333.4 \\
$2004-05$ & 0.0 & 0.0 & 38.1 & 6.4 & 38.9 & 28.8 & 112.2 \\
$2005-06$ & 2.1 & 19.0 & 0.0 & 0.0 & 3.0 & 125.9 & 150.0 \\
$2006-07$ & 4.6 & 0.0 & 0.0 & 80.3 & 47.6 & 100.9 & 233.4 \\
$2007-08$ & 0.0 & 0.0 & 17.1 & 1.7 & 33.8 & 40.4 & 93.0 \\
Mean & 11.0 & 11.3 & 16.7 & 17.7 & 22.0 & 62.1 & 140.8 \\
$2008-09$ & 0.0 & 0.0 & 0.0 & 0.1 & 0.0 & 0.0 & 0.1 \\
\hline
\end{tabular}

Source: National Meteorological Observatory of Rampur, National Maize Research Program, Chitwan

The similar results were found in maize (Amgain, 2011) and wheat (Ghosh et al., 2000; Paul and Sarker 2000; Sandhu et al., 1999). Late planting decreased the duration of all phenological stages compared to normal planting associated with less average temperature, more foggy days with less bright sunshine hours especially upto flowering stages of wheat. Sandhu et al. (1999) and Paul and Sarker (2000) also reported that requirement of heat units decreased for different phenological stages with delay in sowing of wheat. However, the late planted wheat abruptly come to flowering and maturity with in short time period due to high temperature after January months and the accumulative GDD records were also comparatively higher due to higher temperatures. The requirements of HTU for normal planting conditions were significantly higher than the late planting conditions with few exceptions with some cultivars and planting dates (Table 2). The variation in sunshine hours at different developmental stages of wheat has affected the magnitudes of the HTU though there was higher GDD at advanced growth stages. The random trend of HTU for different phenological stages was also found to be for late sown wheat (Rajput et al., 1987; Paul and Sarker, 2000; Hauqe et al., 2000).

\section{Heat and radiation use efficiencies and grain yields}

It was observed that all wheat cultivars were more efficient to show more heat and radiation use efficiencies at normal growing condition than the late growing 
conditions (Table 3). The date of planting is major governing factors in crop production and considered as low-cost high monetary returned technology under best management conditions. The wheat varieties planted on November 15 produced higher yield than subsequent late plantings. The results are in accordance to Amgain (2011) in maize, Paul and Sarker (2000) in wheat, Rao et al.(2000) in cluster bean and Singh et al. (1998) in pearlmillet.

The percentage reduction in yield was more for November 15 vs December 1 sowing than the December 1 vs December 15 planting for short duration NL-297 variety but the vice-versa with mid andlate maturing varieties RR-21, BL-1473 and BL-1022 (Table 4) suggesting that early planting is must for long duration varieties. This might be due to the late planting of wheat resulted less dry matter and metabolized less photosynthate as the result of less growing degree days and helio-thermal units. Rao and Singh (2007) have also found the lesser yield of pearlmillet when planted delayed in Rajsthan, India.

Table 2. Calendar days, accumulated growing degreedays (GDD), and helio-thermal units (HTU) during different pheno-phases of wheat in Chitwan.

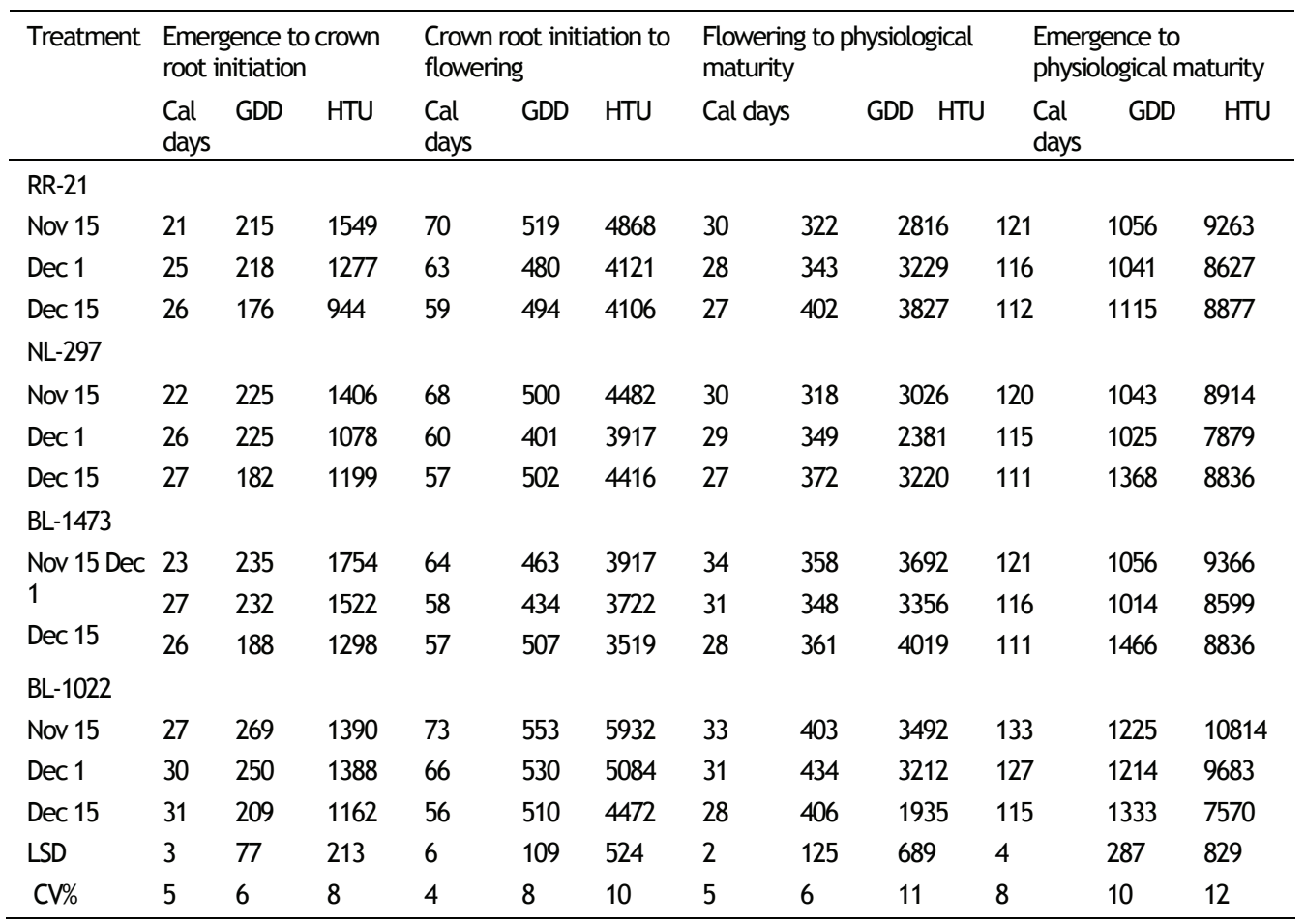


Table 3. Radiation, dry matter, heat and radiation use efficiency of wheat cultivars in Chitwan.

\begin{tabular}{llllll}
\hline Treatment & $\begin{array}{l}\text { Radiation } \\
\mathrm{MJ} / \mathrm{m}^{2} / \text { day }\end{array}$ & $\begin{array}{l}\text { Drymatter } \\
\mathrm{Kg} / \mathrm{ha}\end{array}$ & $\begin{array}{l}\mathrm{HUE} \\
\mathrm{Kg} /{ }^{\circ} \mathrm{C} \text { day }\end{array}$ & $\begin{array}{l}\mathrm{HTUE} \\
\mathrm{Kg}{ }^{\circ} \mathrm{C} \text { hour }\end{array}$ & $\begin{array}{l}\mathrm{RUE} \\
\mathrm{Kg} / \mathrm{MJ}\end{array}$ \\
\hline RR-21 & & & & & \\
Nov 15 & 2350 & 5735 & 5.43 & 0.62 & 2.44 \\
Dec 1 & 2279 & 5526 & 5.31 & 0.64 & 2.42 \\
Dec 15 & 2222 & 4972 & 4.43 & 0.56 & 2.24 \\
NL-297 & & & & & \\
Nov 15 & 2350 & 4851 & 4.65 & 0.54 & 2.06 \\
Dec 1 & 2250 & 4474 & 4.36 & 0.57 & 1.99 \\
Dec 15 & 2204 & 4166 & 3.05 & 0.47 & 1.89 \\
BL-1473 & & & & & \\
Nov 15 & 2350 & 6838 & 6.48 & 0.73 & 2.91 \\
Dec 1 & 2280 & 6185 & 6.10 & 0.72 & 2.71 \\
Dec 15 & 2204 & 5588 & 3.81 & 0.63 & 2.53 \\
BL-1022 & & & & & \\
Nov 15 & 2405 & 7722 & 6.30 & 0.71 & 3.15 \\
Dec 1 & 2396 & 7350 & 6.05 & 0.76 & 3.07 \\
Dec 15 & 2294 & 6652 & 4.99 & 0.88 & 2.90 \\
\hline
\end{tabular}

Table 4. Grain yield $(\mathrm{kg} / \mathrm{ha})$ and yield reduction (\%) due to delayed planting in different wheat cultivars

\begin{tabular}{llcclcc}
\hline Wheat cultivars & \multicolumn{2}{c}{ Grain yield (kg/ha) } & \multicolumn{4}{c}{ Yield reduction (\%) due to late sowing } \\
& Nov 15 & Dec 1 & Dec 15 & Nov 15 vs & Dec 15 vs & Nov 15 vs \\
& & & & Dec 1 & Dec 15 & Dec 15 \\
\hline RR-21 & 2179 & 1934 & 1625 & 11.25 & 15.99 & 25.44 \\
NL-297 & 1815 & 1520 & 1356 & 16.27 & 10.79 & 25.31 \\
BL-1473 & 2872 & 2289 & 1896 & 20.31 & 17.15 & 33.98 \\
BL-1022 & 3089 & 2646 & 2145 & 14.34 & 18.93 & 30.56 \\
\hline
\end{tabular}

\section{Correlation and regression}

Correlation between the calendar days and AGDD and HTU indicated significant relationship between calendar days and AGDD and HTU during emergence to physiological maturity stage of all promising wheat cultivars while negatively correlated and non-significant during emergence to crown root initiation stages for all wheat cultivars (Table 5). 
Table 5. Correlation coefficients between calendar days and AGDD and HTU during different pheno-phases of wheat under different planting dates

\begin{tabular}{lllllllll}
\hline Phenophases & RR-21 & & NL-297 & & BL-1473 & & BL-1022 \\
& AGDD & HTU & AGDD & HTU & AGDD & HTU & AGDD & HTU \\
\hline $\begin{array}{l}\text { Emergence to crown root } \\
\text { initiation }\end{array}$ & -0.614 & -0.924 & -0.654 & -0.843 & -0.331 & -0.732 & -0.886 & -0.701 \\
$\begin{array}{l}\text { Crown root initiation to } \\
\text { flowering }\end{array}$ & 0.751 & 0.939 & -0.227 & -0.980 & -0.248 & 0.920 & 0.991 & 0.981 \\
$\begin{array}{l}\text { Flowering to physiological } \\
\text { maturity }\end{array}$ & -0.897 & -0.951 & -0.961 & -0.401 & -0.204 & -0.493 & 0.033 & 0.972 \\
$\begin{array}{l}\text { Emergence to physiological } \\
\text { maturity }\end{array}$ & 0.993 & 0.652 & 0.698 & 0.132 & 1.0 & 0.675 & 0.913 & 0.993 \\
\hline
\end{tabular}

RR-21 and BL-1022 being quite longer in duration than NL-297the flowering to physiological maturity stages was found to be significantly correlated. The correlation was found variable and inconsistent on NL-297 and Bl-1473 especially during crown root initiation to flowering and this might be due to the shorter phase of these cultivars due to lesser accumulated temperature and sunshine hours.

Following regression equations were established to predict the phenology of wheat using AGDD and HTU in all wheat cultivars.

$$
\begin{array}{ll}
\text { RR-21: } Y=79.74+0.0132 \text { AGDD }+0.001978 \mathrm{HTU} & \mathrm{R}^{2}=0.98 \\
\text { NL-297: } Y=134.84+0.0430 \text { AGDD }-0.094 \mathrm{HTU} & \mathrm{R}^{2}=0.49 \\
\mathrm{BL}-1473: \mathrm{Y}=\quad 82.92+0.0214 \text { AGDD }-0.0004 \mathrm{HTU} & \mathrm{R}^{2}=0.99 \\
\mathrm{BL}-1022: \mathrm{Y}=\quad 100.86-0.016 \text { AGDD }+0.0046 \mathrm{HTU} & \mathrm{R}^{2}=0.83
\end{array}
$$

Physiological maturity can be predicted using AGDD and HTU which accounted for 99, 99, and 83 percent, for RR-21, BL-1473 and BL-1022, respectively.

\section{CONCLUSIONS}

Wheat cultivars BL-1473, BL-1022 and RR-21 were better to show greater stability to solar energy, accumulated growing degree days (AGDD) and heat use efficiency than the NL-297 cultivar. NL-297 is suggested for late sowing and the less reduction in yield between Dec 1 and Dec 15 plantings. By sowing the wheat on 15 November, the higher and stable heat, radiation and helio-thermal indices were achieved and thus the higher grain yield. The agro-meteorological indices could therefore be helpful in predicting the phenolgoy, growth and yields of wheat in Chitwan. However, more research is needed in other agro-ecological areas to validate the output further. 


\section{ACKNOWLEDGEMENT}

The datasets presented in this study was taken from the field study of Agronomy Farm where the author was Farm Superintendent. The supportive financial helps on seeds, fertilizers and laborers from IAAS Rampur Campus was kindly thankful. The author has been very much thankful to NMRP, Rampur for providing the daily weather records to accomplish this study.

\section{REFERENCES}

Amgain, L.P. 2011. Accumulated heat unit and phenology of different maize cultivars as influenced by planting time and seasons. J Inst. Agric. Anim. Sci. 32 :143-150.

Doraiswamy, P. C. and D. R. Thompson. 1982. A crop moisture stress index for large areas and its application in the production of spring wheat phenology. Agril Meterol 27: 290294.

Ghosh, D.C., P. Nandi and B. De. 2000. Phenological development and productivity of wheat (Triticum aestivum L.) at different dates of sowing. Indian J. Agric. Sci. 70(6): 390-395.

Giri, G.S. 1998. Response of rice culture on subsequent wheat grain yield. Wheat Research Report (In) Proc. National Winter Crops Technology Workshop (17-20 Dec.1998) NARC and CYMMIT Publications: pp 15-18.

Hobbs, P.R. 2000. The rice-wheat consortium: An eco-regional initiative of the Consultative Group on International Agricultural Research (CGIAR) for the Indo-Gangetic Plains of South Asia. Sustainable Agriculture: Policy and Direction: CIMMYT, Kathamandu pp. 199-210.

Jones, J. W., G. Hoogenboom, C.H. Porter, K.J. Bootee, W. D. Batchelor, L. A. Hunt, P. W. Wilkens, U. Singh, A. J. Gijsman and J.T. Ritchie. 2003. The DSSAT Cropping System Model. European Journal of Agronomy 18:235-265.

NWRP. 2010. Annual Report, National Wheat Research Program, Bhairahawa, Rupandehi, Nepal.

Paul, N.K. and D. K. Sarker. 2000. Accumulated heat units and phenology relationships in wheat as influenced by sowing dates. Bangladesh J. Bot. 29(1): 49-54.

Rajput, R.P., M. R. Deshmukh and V. K. Paradkar. 1987. Accumulated heat unit and phenology relationships in wheat (Triticum aestivum L.) as influenced by planting dates under late sown conditions. J Agron. Crop Sci. 159: 345-348.

Rao, A. S and R. S. Singh. 2007. Evapo-transpiration rates and water-use efficiency of HHB 67 pearl millet (Pennisetum glaucum) under arid climatic conditions. Indian J. Agric. Sci. 77 (12): 810-13.

Rao, A. S., R. S. Singh, N. L. Joshi and Y. S. Ramakrishna. 2000. Evapo-transpiration, water and radiation-utilization of cluster bean (Cyamopsis tetragonoloba). Indian J. Agric. Sci. 70 (1): 149-153.

Rao, V. U. M., D. Singh and R Singh. 1999. Heat use efficiency of winter crops in Haryana. Journal of Agro-meteorology 1 (2): 143-148.

Reddy, S.R. 2005. Agronomy of Field Crops. Kalyani Publishers, Second Revised Edition. Kalyani Publishers, Ludhiana, India. pp. 9-124.

Reddy, D. R., G. Sreenivas, T. Ratnasudhakhar and S. B. S. N. Rao. 2004. Growth of rice varieties interms of growing degree days under Telengana conditions. Journal of Agrometeorology 6(2): 274-277. 
Ritchie, J. T. and D. S. Nesmith. 1991. Temperatures and crop development. Modeling plant and soil systems. Agronomy Monograph No. 31, ASA-CSSA-SSSA, Madison, WI53711, USA.

Sandhu, I. S., A. R. Sharma and H. S. Sur. 1999. Yield performance and heat unit requirement of wheat (Triticum aestivum L.) varieties as affected by sowing dates under rainfed conditions. Indian J. Agric. Sci. 69: 175- 179.

Sastry, C.V.S., T.R. Rao and Joydeep Mukharjee. 2000. PAR distribution in mustard (Brassica juncea L. variety Pusa Bold) crop canopy: J Agro-meteorology 2 (1): 15-20.

Sharma, P. P., R. R. Khakural, B. Chhetri and T. B. Khatri Chhetri. 1984. Contribution of dew in winter wheat in Rampur, Chitwan. J. Inst. Agric. Anim. Sci. 5:71-82.

Sikder, S. 2009. Accumulated heat unit and phenology of wheat cultivars as influenced by late sowing heat stress condition. J Agric Rural Dev 7 (1 \&2): 57-64.

Singh, R. S. N. L. Joshi and H. P. Singh. 1998. Pearl millet phenology and growth in relation to thermal time under arid environment. Journal of Agronomy and Crop Science 180(2): 83-91.

Sreenivas, G., M. Devender Reddy and D. Raji, Reddy. 2010. Agro-meteorological indices in relation to phenology of aerobic rice. Journal of Agro-meteorology 12 (2): 241-244. 